\title{
Assessing the response of vegetation photosynthesis to meteorological drought across northern China
}

\author{
Hao-jie $\mathrm{Xu}^{1}$, Xin-Ping Wang ${ }^{2}$, C. Y. Zhao ${ }^{1}$, and Xue-mei Yang ${ }^{3}$ \\ ${ }^{1}$ Lanzhou University \\ ${ }^{2}$ Chinese Academy of Sciences \\ ${ }^{3}$ Gansu Desert Control Research Institute
}

May 5, 2020

\begin{abstract}
Satellite-based solar-induced chlorophyll fluorescence (SIF) has the potential for an early detection and accurate impact assessment of meteorological drought on vegetation photosynthesis. However, how the response of satellite SIF to meteorological drought varies under different climatic conditions and biome types remains poorly understood. In this study, we determined the drought time-scale at which the vegetation photosynthesis response was highest based on the standardized precipitation evapotranspiration index (SPEI) and satellite SIF, and examined how the sensitivity of SIF signals from different ecosystems to drought varied along an aridity gradient in northern China. The results showed that spatial variability of the annual maximum SIF was constrained by wetness conditions and biome types. Annual maximum SIF was positively correlated with SPEI in $57.9 \%$ of vegetated lands ( $\mathrm{P}<0.05) .34 .8 \%$ of humid ecosystems were characterized by a significant SIF-SPEI correlation $(\mathrm{P}<$ 0.05). This percentage reached $44 \%, 71.4 \%$ and $86.2 \%$ for arid, sub-humid and semi-arid ecosystems, respectively. The variation of SIF-SPEI correlations was a Gaussian function of the aridity index (AI), with the highest SIF-SPEI correlation appearing in the AI bin of 0.4 (0.37-0.46). The drivers for this pattern were vegetation composition and water availability. The variation of SIF time-scales in response to SPEI was a linear function of the AI, but the slope varied among biomes. To summarize with increasing aridity drought-induced declines in vegetation photosynthesis will be quicker and more significant.
\end{abstract}

\section{Hosted file}

Manuscript.docx available at https: //authorea.com/users/302118/articles/432491-assessing-theresponse-of-vegetation-photosynthesis-to-meteorological-drought-across-northern-china 

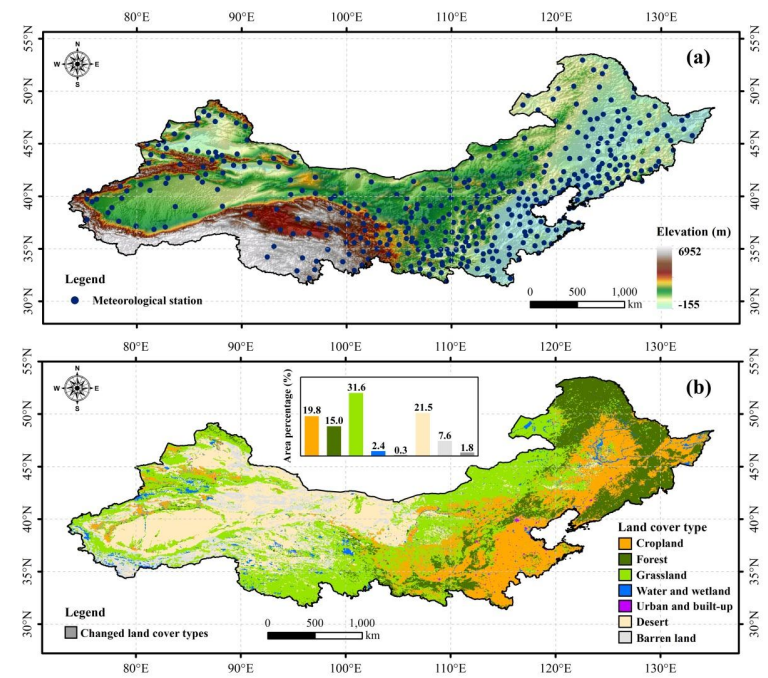

Fig.1 Spatial distribution of the elevation, meteorological stations (a) and land cover types (b) over northern China. The inset graph shows the proportion of each land cover type. Changed areas are extracted based on maps of the land cover type in 2000 and 2015, respectively. 